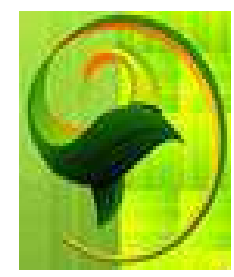

Journal Humanities: Jurnal Pengabdian kepada Masyarakat Volume 1, Nomor 1, Bulan Juni, 2020.

E - ISSN 2715-5471

Doi: https://doi.org/10.24036/jha.0102.2019.06

\title{
Dissemination and Training of Early Childhood Motion Skill Level Development for PAUD / Kindergarten and Elementary Teachers in Lima Puluh Kota District
}

\author{
${ }^{1}$ Lucy Pratama Putri, ${ }^{2}$ Ibnu Andli Marta, ${ }^{3}$ Oktarifaldi, ${ }^{4}$ Jonni, ${ }^{5}$ Yulifri, ${ }^{6}$ Kibadra, ${ }^{7}$ Ali Asmi, \\ ${ }^{8}$ Hasriwandi Nur, ${ }^{9}$ Nirwandi, ${ }^{10}$ Erizal N, ${ }^{11}$ Syahrial Bakhtiar \\ ${ }^{1234567891011}$ Fakultas Ilmu Keolahragaan, Universitas Negeri Padang, Indonesia \\ Email: 1ucy.prtama@,fik.unp.ac.id ${ }^{1}$, ibnuandlimarta@fik.unp.ac.id ${ }^{2}$, oktarifaldi88@fik.unp.ac.id ${ }^{3}$, \\ drs.jonni.mpd@gmail.com ${ }^{4}$, yulifri@,fik.unp.ac.id ${ }^{5}$, kibadra@fik.unp.ac.id ${ }^{6}$, aliasmi@,fik.unp.ac.id ${ }^{7}$, \\ hasriwandinur@fik.unp.ac.id ${ }^{8}$, nirwandi@fik.unp.ac.id ${ }^{9}$, erizaln@,fik.unp.ac.id ${ }^{10}$, \\ syahrial@,fik.unp.ac.id ${ }^{11}$
}

\begin{abstract}
Abstra
Some of the results of studies that have been conducted on basic early Indonesian fundamental motor skills children, especially in West Sumatra, are found to be at the lowest level. Observations made on several teachers in West Sumatra show that on average they have very limited insight into fundamental motor skills and how to arrange fundamental motor skills. Previous research states that fundamental motor skills cannot develop by themselves, but through continuous learning and training stages. Therefore, PAUD teachers are expected to be skilled in compiling children's fundamental motor skills so that the objectives of early childhood education can be achieved as they should. This service activity aims to: (a) PAUD / TK teachers understand what fundamental motor skills are. (b) PAUD / TK teachers can understand fundamental motor skills. (c) PAUD / TK teachers can understand how to use the TGMD-2 instrument (d) PAUD / TK teachers can understand how to evaluate fundamental motor skills.
\end{abstract}

Keywords: Dissemination and Training, Motion Skill Level

\begin{abstract}
Abstrak
Beberapa hasil penelitian yang telah dilakukan mengenai keterampilan gerak dasar anak usia dini Indonesia, khususnya di Sumatera Barat ditemukan bahwa berada pada level terendah. Observasi yang telah dilakukan terhadap beberapa guru yang ada di Sumatera Barat memperlihatkan bahwa ratarata mereka memiliki wawasan yang sangat terbatas mengenai keterampilan gerak dasar dan cara menyusun pembelajaran gerak dasar. Penelitian terdahulu menyebutkan bahwa keterampilan gerak dasar tidak dapat berkembang dengan sendirinya, melainkan melalui tahap pembelajaran dan latihan yang berkesinambungan. Oleh sebab itu, guru-guru PAUD diharapkan dapat terampil dalam menyusun pembelajaran gerak dasar anak agar tujuan dari penyelenggaraan pendidikan anak usia dini dapat dicapai sebagaimana mestinya. Kegiatan pengabdian ini bertujuan agar: (a) guru-guru PAUD/TK dapat memahami apa itu keterampilan gerak dasar. (b) guru-guru PAUD/TK dapat memahami pembelajaran gerak dasar. (c) guru-guru PAUD/TK dapat memahami bagaimana cara menggunakan instrument TGMD-2 (d) guru-guru PAUD/TK dapat memahami cara melakukan evaluasi keterampilan gerak dasar.
\end{abstract}

Keywords: Sosialisasi dan Pelatihan, Level Kemampuan Gerak

\section{ANALISIS SITUASI}

Usia dini merupakan periode awal yang paling penting dan mendasar sepanjang rentang pertumbuhan serta perkembangan kehidupan manusia. Masa ini ditandai oleh berbagai periode penting yang fundamental dalam kehidupan anak selanjutnya sampai periode akhir perkembangannya. Dalam hal ini Bakhtiar (2019) menyampaikan, upaya yang dapat dilakukan oleh negara untuk menghadapi tantangan global salah satunya dengan menyiapkan Sumber Daya Manusia (SDM) yang handal. Sumber daya handal yang dimaksud tidak dapat bergitu saja tercipta dalam waktu singkat, salah satu upaya adalah memberikan perhatian terhadap pendidikan anak usia dini. Periode ini juga dikenal 


\section{Dissemination and Training of Early Childhood Motion Skill Level Development for PAUD / Kindergarten and Elementary Teachers in Lima Puluh Kota District}

${ }^{1}$ Lucy Pratama Putri, ${ }^{2}$ Ibnu Andli Marta, ${ }^{3}$ Oktarifaldi, ${ }^{4}$ Jonni, ${ }^{5}$ Yulifri, ${ }^{6}$ Kibadra, ${ }^{7}$ Ali Asmi, ${ }^{8}$ Hasriwandi Nur, ${ }^{9}$ Nirwandi, ${ }^{10}$ Erizal N,

dengan istilah golden age atau usia emas dalam tahap pertumbuhan dan perkembangan kemampuan gerak dasar anak.

Golden age ini dimulai pada umur 3 sampai 10 tahun yang mampu menopang keterampilan gerak dasar atau fundamental motor skill anak (Liu dalam Bakhtiar et all, 2019). Pada masa ini akan memungkinkan anak untuk berinterkasi dengan lingkunganya agar kemampuan gerak dasar yang mereka miliki dapat semakin berkembang dan mempelajarai kemampuan baru untuk beralih ke level berikutnya (Graham, 1987; Belka, 2004; Pappa, 2005; Thomas, Lee, \& Thomas, 1988; Gallahue \& Ozmun, 1998; Chatzipanteli A. et al, 2005; Mandigo, Francis, Lodewyk, 2007 dalam Tsapakidou et. all, 2014).

Intervensi yang diberikan pada masa ini mmapu menopanng proses pertumbuhan dan perkembangan fisik, motorik, social, emosional dan kognitif anak. Hal yang perlu kita pahami adalah, dalam pertumbuhan dan perkembangan fisik serta motorik anak ada yang dikenal dengan istilah Motor Behavior atau kebiasaan gerak. Motor behavior ini mencangkup tiga fase yang dimulai dari motor control atau kontrol gerak, kemudian dilanjutkan pada motor learning atau belajar bergerak dan dilanjutkan dengan fase motor development atau perkembangan gerak. Pada fase motor development inilah kemampuan gerak dasar anak dapat kita latih agar mencapai tahap maksimal.

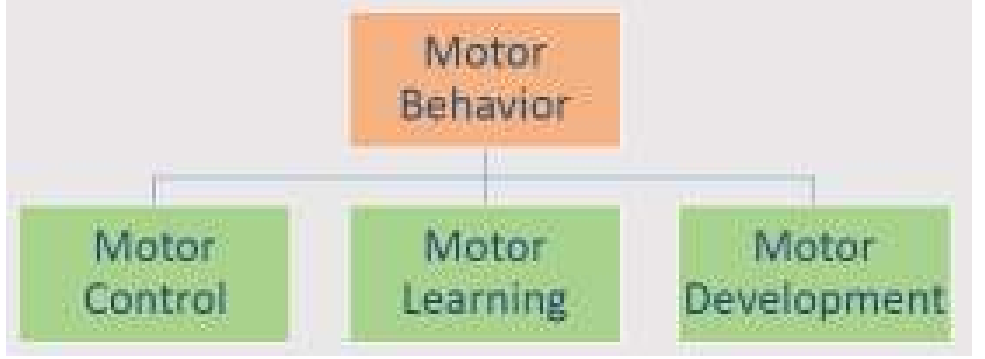

Gambar 1. Umbrella Term

Keterampilan gerak dasar dianggap sebagai dasar untuk kompetensi gerak (Pope et all 2011) serta sebagai keterampilan motorik kompleks dan terspesialisasi yang diperlukan untuk keberhasilan partisipasi anak dalam melakukan aktivitas sehari-hari, seperti kegiatan sosial, olahraga dan masih banyak lagi (Gallahue, Ozmun, \& Goodway, 2011; Sugden \& Wade, 2013; Valtr, Psotta, \& Abdollahipour, 2016 dalam Kokštejn et all 2017). Kemampuan gerak dasar dibagi kedalam dua kelompok besar, yaitu kemampuan objek kontrol dan lokomotor (Gallahue, Ozmun dan Goodway 2012 dalam Bakhtiar, 2015:10). Kemampuan lokomotor merupakan gerak yang memindahkan tubuh dari satu titik ke titik lain (Barnett et al., 2008 dalam Ali et all 2017) sedangkan kemampuan Objek kontrol adalah kemampuan meningkatkan kinerja otot-otot untuk melakukan suatu gerakan, dan memiliki kemampuan yang bagus untuk membuat gerakan yang terkontrol dan tepat dengan suatu objek (David L. Gallhue, john C. Ozmun dan jacqueline. D. Goodway (2012).

Pada masa-masa awal perkembangan gerak, kemampuan gerak dasar ini sering diabaikan oleh para pendidik (Ulrich, 2000). Pentingnya mengajarkan keterampilan gerak dasar ininbelum begitu disadari oleh guru PAUD/TK yang ada di Indonesia. Mereka juga belum dibekali dengan ilmu yang matang untuk mengajarkan pembelajaran gerak. Ironisnya, di Sumatera Barat bahkan guru belum memiki, pengetahuan serta wawasan mengenai gerak dasar pada anak (Bakhtiar \& Famelia 2017 dalam Oktarifaldi et all, 2019). Padahal pada masa ini kemampuan gerak anak mulai muncul dan berkembang. Setiap gerakan yang dilakukan oleh anka, akan mereka simpan dalam memorinya sebagai koleksi dari serangkaian gerak yang mereka lakukan. Semakin banyak gerak yang anak lakukan, maka akan semakin banyak koleksi gerak yang mereka miliki sehingga menjadikan anak lebih luwes dalam melakukan aktivitas gerak (Asnaldi \& Kibadra, 2019). Koleksi gerakan yang dimiliki anak akan menjadi salah satu indicator untuk melihat keterlambatan perkembangan dan memperbaiki kesalahan gerakan-gerakan yang ditampilkan agar tidak menjadi permanen dan menimbulkan permasalahan dimasa mendatang.

Kesalahan gerak yang dialami anak juga akan mengganggu perkembangan aspek social anak. Biasanya, anak yang tidak terampil akan selalu dijadikan cemoohan dan pilihan terakhir dalam berbagai aktivitas fisik serta olahraga yang dilakukan oleh teman-teman sebayanya. Lama kelamaan keadaan yang demikina ini secara tidak sadar akan menurunkan tingkat kepercayaan diri anak. Anak 
akan lebih memilih menyendiri dibandingkan ikut berpartisipasi dengan teman sebaya. Oleh sebab itu, melakukan evaluasi terhadap pertumbuhan dan perkembangan fisik dan motorik anak harus dilakukan sedini mungkin.

Namun tidak semua orang paham tentang pentingnya mengajarkan kemampuan gerak dasar pada anak. Kebanyakan individu berfikir bahwa kemampuan gerak dasar bukanlah hal penting karena melulu anak diminta bergerak untuk meningkatkan kemampuan gerak mereka tanpa memperhatikan aspek kognitif dan afektif anak. Padahal ketika anak melakukan aktivitas gerak, anak tidak hanya semata-mata melatih kemampuan geraknya. Melalui aktivitas gerak yang anak lakukan memberikan dampak positif terhadap kemampuan kognitif yang disebabkan oleh perubahan fisiologi tubuh manusia Contohnya, peningkatan kadar faktor neurotropik yang diturunkan dari otak (BDNF) dapat memfasilitasi pembelajaran dan mempertahankan fungsi kognitif dengan meningkatkan plastisitas sinaptik dan berfungsi sebagai agen neuroprotektif, yang mengarah pada peningkatan aktivitas neuroelektrik dan peningkatan sirkulasi otak (Hilman et all 2008 dalam Zipporah et all 2016). Serta juga banyak yang berpandangan bahwa kemampuan gerak dasar dinilai tidak perlu untuk diajarkan karena pada dasarnya setiap anak selalu bergerak. Lagi-lagi pandangan demikian adalah pandangan yang sangat salah. Sebenarnya, kemampuan gerak dasar harus benar-benar diajarkan pada masa-masa awal pertumbuhan dan perkembangan karena kemmapuan gerak dasar ini tidak akan berkembang seiring dengan bertambahnya usia seorang anak .

Pengabdi telah melakukan kegiatan pelatihan dalam rangka meningkatkan pengetahuan, wawasan dan keterampilan mengajar dalam mengajarkan kemampuan gerak dasar anak usia dini pada guru-guru PAUD. Kegiatan pengabdian ini pengabdi lakukan didasarkan atas beberapa temuan yang pengabdi dapatkan serta dukungan dari penelitian sebelumnya yang mengatakan bahwa kemampuan mengajar yang dimiliki oleh guru pada jenjang pendidikan anak usia dini masih rendah (Yusria, 2012 dalam Oktarifaldi et all, 2019). Penelitian lain menyebutkan bahwa guru-guru PAUD memiliki pengetahuan yang rendah mengenai keterampilan motorik anak (Famelia et all 2016).

Pada kesempatan ini pengabdi menjelasakan mengenai hubungan linear yang antara mengajarkan kemampuan gerak dasar dengan kemampuan kognitif anak (Hartman et all 2011 dalam Korbecki dan Rokita, 2017). Maka dari itu, kemampuan gerak dasar ini tidak dapat dipandang sepele karena juga menopang kemampuan kognitif anak. Dari diskuis yang pengabdi lakukan dengan guruguru PAUD, pengabdi mendapati bahwa selama ini yang mereka pahami bahwa kemampuan gerak dan kemampuan kognitif tidak saling berhubungan. Jika mengajarkan gerak pada anak, maka hanya akan meningkatkan fungsi motorik saja. Begitupun sebaliknya ketika mereka mengajarkan kemampuan kognitif, maka yang akan meningkat hanya fungsi otak saja.

Program pengabdian kepada masyarakat ini pengabdi lakukan berdasarkan temuan penelitian terdahulu serta studi dan observasi yang langsung pengabdi lakukan diberbagai Kota dan Kabupaten di Sumatera Barat. Hasil observasi dan studi awal tersebut, ditemui permasalahan sebagai berikut: (a) Sebagian besar guru-guru PAUD/TK belum memahami apa itu keterampilan gerak dasar. (b) Sebagian besar guru-guru PAUD/TK belum memahami pembelajaran gerak dasar. (c) Sebagian besar guru-guru PAUD/TK belum memahami bagiamana cara menggunakan instrument TGMD-2 (d) ) Sebagian besar guru-guru PAUD/TK belum memahami cara melakukan evaluasi keterampilan gerak dasar.

Kedepanya pengabdi mengingkan bahwa kegiatan pengabdian yang telah pengabdi lakukan dapat memberikan pandangan serta wawasan yang baru pada guru PAUD yang ada di Kabupaten Lima Puluh Kota. Selain itu pengabdi juga ingin melakukan pembinaan sebagai bentuk kepedulian pengabdi terhadap peningkatan kemampuan gerak dasar anak. Dengan adanya kegiatan ini pengabdi berharap dapat melakukan pembinaan dan monitoring pada guru-guru PAUD serta melakukan evaluasi terhadap pembelajaran gerak yang telah dirancang dan diterapkan. Monitoring dan evaluasi ini pengabdi lakukan agar tujuan utama dari pembelajaran keterampilan gerak dapat tercapai sebagaimana mestinya. 


\section{Dissemination and Training of Early Childhood Motion Skill Level Development for PAUD /}

Kindergarten and Elementary Teachers in Lima Puluh Kota District

${ }^{1}$ Lucy Pratama Putri, ${ }^{2}$ Ibnu Andli Marta, ${ }^{3}$ Oktarifaldi, ${ }^{4}$ Jonni, ${ }^{5}$ Yulifri, ${ }^{6}$ Kibadra, ${ }^{7}$ Ali Asmi, ${ }^{8}$ Hasriwandi Nur, ${ }^{9}$ Nirwandi, ${ }^{10}$ Erizal N,

${ }^{11}$ Syahrial Bakhtiar

\section{SOLUSI DAN TARGET}

Berdasarkan permasalahn yang telah diuruaikan di atas, ada beberapa program yang pengabdi rekomendasikan kepada mitra sebagai solusi yang dapat mitra gunakan dikemudian hari, berupa pembuatan rancangan pembelajaran gerak lokomotor dan objek kontrol. Pengabdi memiliki keinginan yang besar agar buku yang telah dirancang dapat digunakan untuk membantu guru PAUD dalam mengajarkan keterampilan gerak. Kemudian pengabdi juga berkeinginan agar guru PAUD dapat menggunakan instrument Test of Gross Motor Development $2^{\text {th }}$ Edition (TGMD-2) sebagai instrument baku dalam menilai keterampilan gerak anak usia dini.

Ada beberapa hal yang menjadi focus penting dalam kegiatan pelatihan dan pembelajaran gerak dasar juga cara mengukur keterampilan gerak dasar anak usia dini, yaitu:

1. Perhatian mendalam mengenai keterampilan gerak dasar anak usia dini. Diharapkan kepada guruguru PAUD setelah mengikuti kegiatan pelatihan dan pengambangan ini dapat lebih banyak mencari tahu mengenai keterampilan gerak dasar, belajar motorik anak serta pertumbuhan dan perkembangan pada anka usia dini.

2. Pembuatan produk berupa buku mengenai pembelajaran gerak dasar dan instrument tes keterampilan gerak dasar yang dirancang sesederhana mungkin agar mudah digunakan oleh guruguru PAUD yang ada di Kabupaten Lima Puluh Kota.

3. Penilaian dari ahli mengenai produk yang dihasilkan, dalam hal ini ahli ilmu gizi, ahli pertumbuhan dan perkembangan fisik motorik serta ahli gerak dasar. Penilaian produk akhir ini diperlukan agar buku yang disusun memang sudah memenuhi standar dasar dalam pengimplementasian pembelajaran gerak dasar.

4. Guru PAUD/TK yang ada di Kabupaten Lima Puluh Kota dapat menjadi perpanjangan tangan bagi pengabdi untuk menerapkan pembelajaran gerak dasar pada siswa PAUD/TK yang diajar.

\section{METODE PELAKSANAAN}

Secara umum, kegiatan ini bertujuan untuk memberikan latihan demin meningkatkan pengetahuan serta keterampilan guru PAUD/TK yang ada di Kbaupaten Lima Puluh Kota agar dapat mengajarkan pembelajaran gerak, melakukan tes serta evaluasi hasil tes keterampilan gerak dasar anak usia dini. Penting diketahui bahwa kegiatan ini harus bisa dilaksanakan secara berkesinambungan di sekolah masing-masing agar tujuan dari pendidikan anak usia dini dapat tercapai sebagaimana mestinya. Tahap kegiatan pengabdian sebagai berikut :

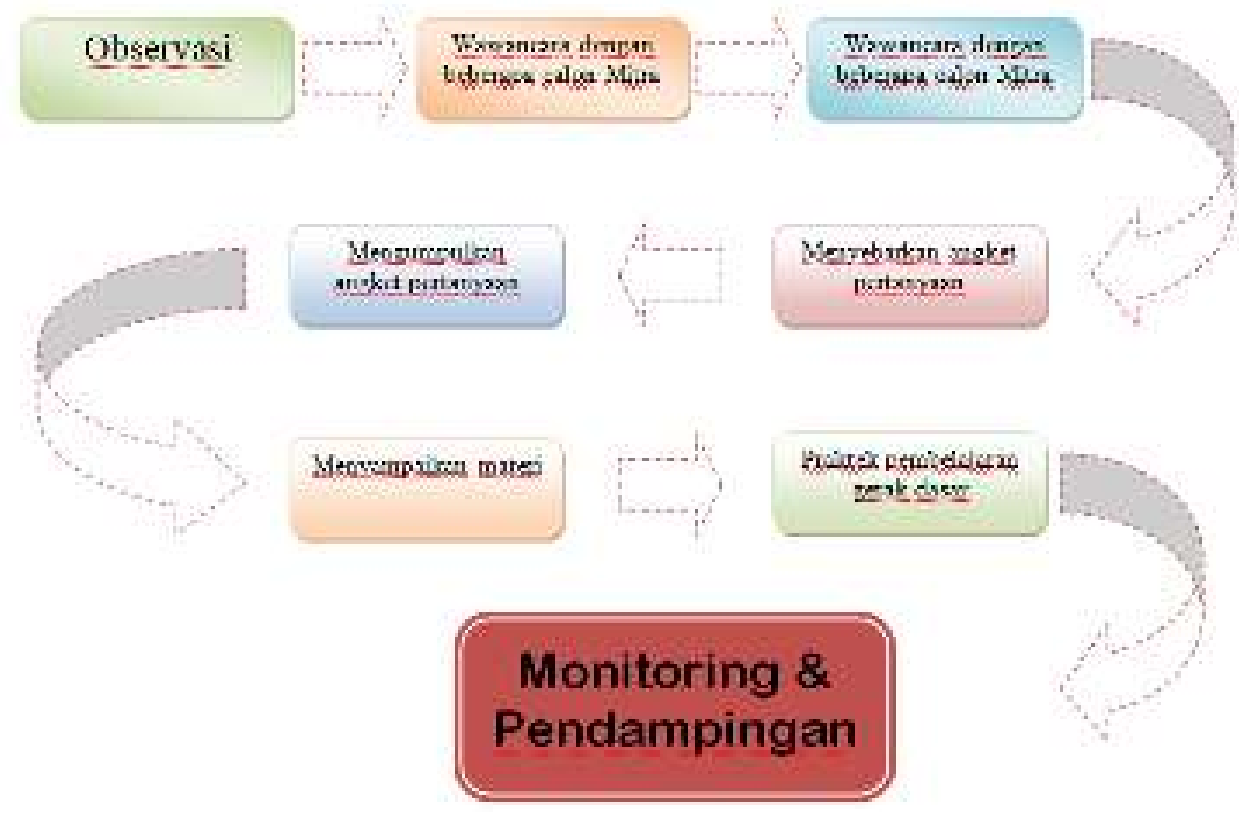

Gambar 2. Alur pelaksanaan kegiatan pengabdian 
Dissemination and Training of Early Childhood Motion Skill Level Development for PAUD /

Kindergarten and Elementary Teachers in Lima Puluh Kota District

${ }^{1}$ Lucy Pratama Putri, ${ }^{2}$ Ibnu Andli Marta, ${ }^{3}$ Oktarifaldi, ${ }^{4} \mathrm{Jonni}$, ${ }^{5}$ Yulifri, ${ }^{6} \mathrm{Kibadra},{ }^{7} \mathrm{Ali}$ Asmi, ${ }^{8} \mathrm{Hasriwandi}$ Nur, ${ }^{9} \mathrm{Nirwandi}$, ${ }^{10} \mathrm{Erizal} \mathrm{N}$,

${ }^{11}$ Syahrial Bakhtiar

Pelaksanaan kegiatan yang pengabdi laksanakan di Kabupaten Lim Puluh Kota tepatnya di aula SPMP Negeri 1 Kecamatan Harau. Sebelum pelaksanaan dilakukan tim pengabdi melakukan komunikasi dengan mitra didahului dengan langkah observasi untuk melihat khalayak sasaran pengabdian (mitra) pengabdian. Hal ini pengabdi lakukan agar nantinya materi yang akan disampaikan memang akan menjadi solusi dari permasalahan yang sedang dialami oleh mitra. Kemudian observasi yang pengabdi lakukan dilanjutkan dengan kegiatan sosialisasi dan diskusi dengan guru dan Kepala Sekolah PAUD/TK serta stakeholders yang ada di Kabupaten Lima Puluh Kota guna menjelaskan maksud dan tujuan dilaksanakanya kegiatan pengabdian. Ada beberapa tahap yang dilaksanakan dalam kegiatan pengabdian kepada masyarakat ini, yaitu:

\section{Pemberian Materi}

Materi yang pengabdi sampaikan dalam kegiatan pengabdian kepada masyarakat kali ini mengenai: (a) wawasan dan pengetahuan tentang pembelajaran gerak dasar, (b) pengetahuan tentang keterampilan gerak dasar, (c) pengetahuan tentang instrument yang digunakan untuk melakukan tes keterampilan gerak dasar, (d) keterampilan dalam mengajarkan gerak dasar dan menggunanakan instrument tes TGMD-2 dalam menggukur keterampilan gerak dasar anak. Dalam pelaksanaan pelatihan ini, peneliti menggunakan beberapa metode penyampaian materi, seperti: metode ceramah, demostrasi, diskusi dan problem solving.

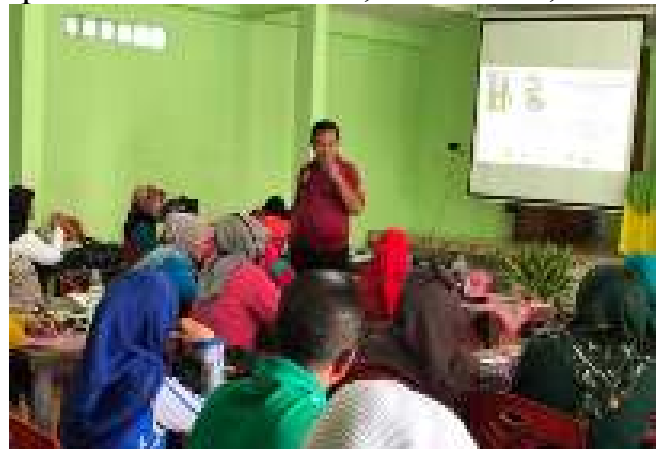

Gambar 3a. Penyampaian Materi Umum

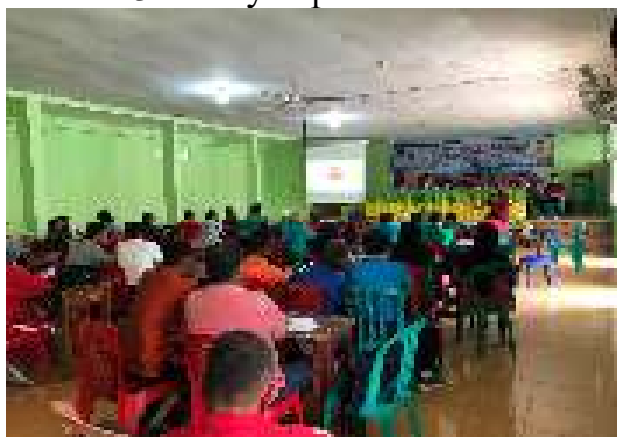

Gambar 4a. Diskusi Materi

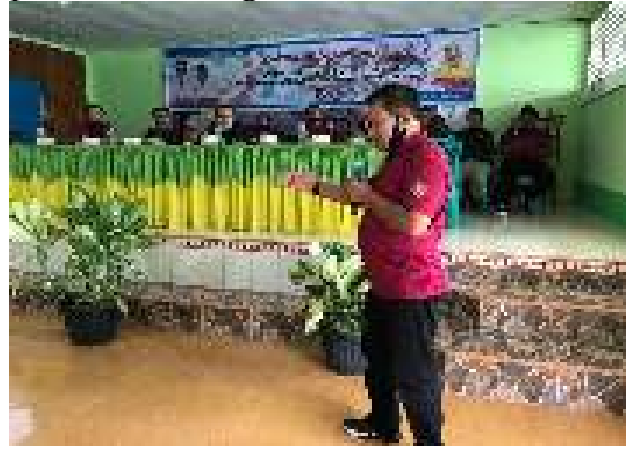

Gambar 3b. Penyampaian Materi Umum

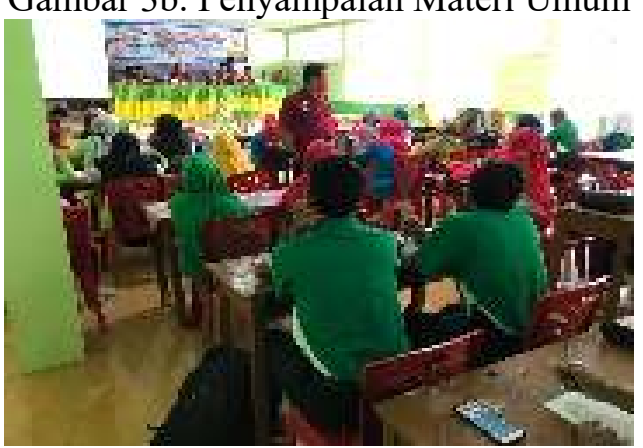

Gambar 4b. Diskusi Materi

\section{Melakukan Diskusi Tentang Materi Pembelajaran Gerak Dasar}

Sesi diskusi dilakukan agar mitra dapat lebih memahami isi dari materi yang disampaikan. Selain itu dengan adanya diskusi antara mitra dan pemateri memungkinkan mitra untuk bertanya lebih rinci mengenai pembelajaran gerak dasar dan pengimplementasianya. Sesi diskusi berlangsung cukup serius karean mitra sangat antusias dengan materi yang disampaikan. Selanjutnya diskusi juga membahas tentang tingkat level kemampuan anak sesuai usinya. Diskusi juga dilengkapai dengan menampilkan video realita di lapangan tingkat kemampuan gerak anak di berbagai kota dan kabupaten yang telah pengabdi dan tim kunjungi dan mengambil sampel. 


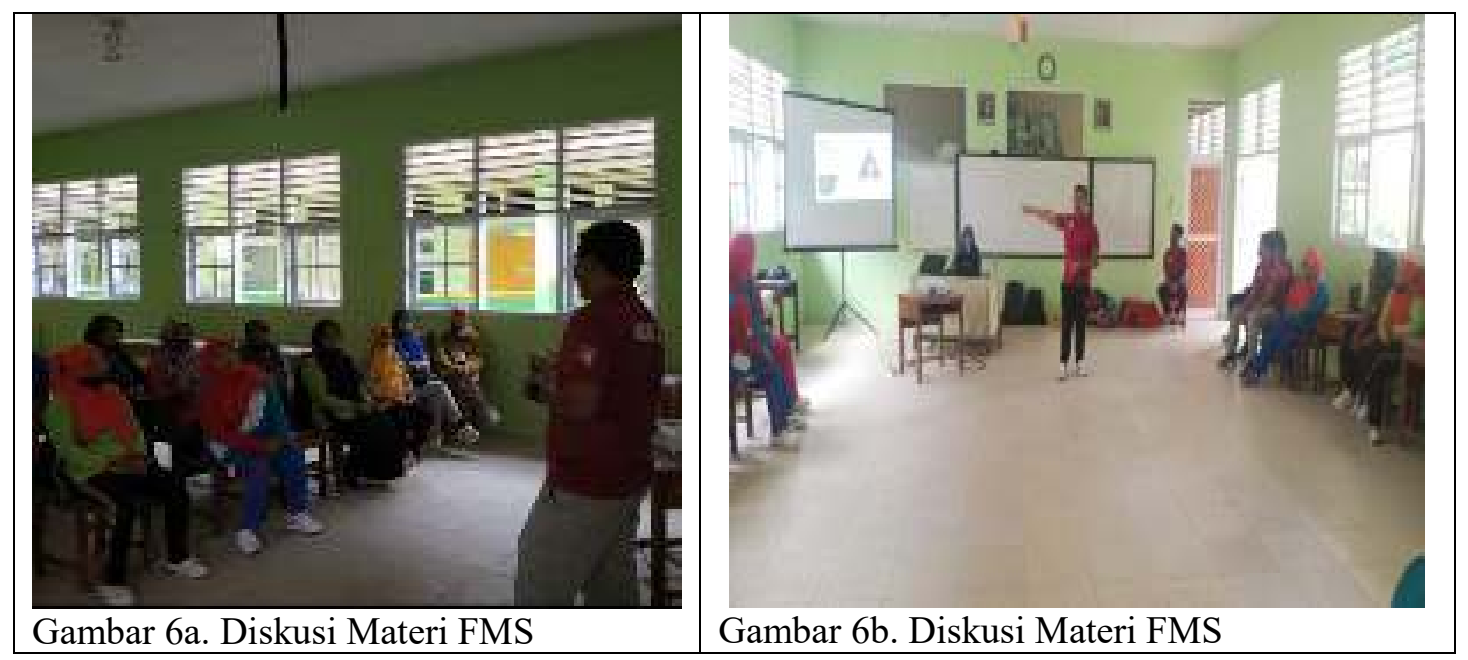

\section{Melakukan Praktek Pembelajaran Gerak Dasar dan Instrumen TGMD-2}

Kegiatan selanjutnya adalah melakukan praktek menyusun pembelajaran gerak dasar dan melakukan tes keterampilan gerak dasar yang terdiri dari kemmapuan objek kontrol dan lokmotor dengan menggunakan instrument TGMD-2. Dalam menyusun pembelajaran gerak dasar, sebaiknya guru PAUD/TK harus memadukan antara kemampuan lokomotor dan objek kontrol, namun jangan terlalu rumit. Karena anak-anak tidak akan mampu mengingat apa yang kita instruksikan. Untuk penggunaan instrument TGMD-2 sebaiknya dimulai dengan item test yang tidak terlalu banyak membutuhkan energy bagi tubuh anak, baru kemudian dilanjutkan pada itemitem yang lebih sulit agar item yang ditest bisa maksimal.

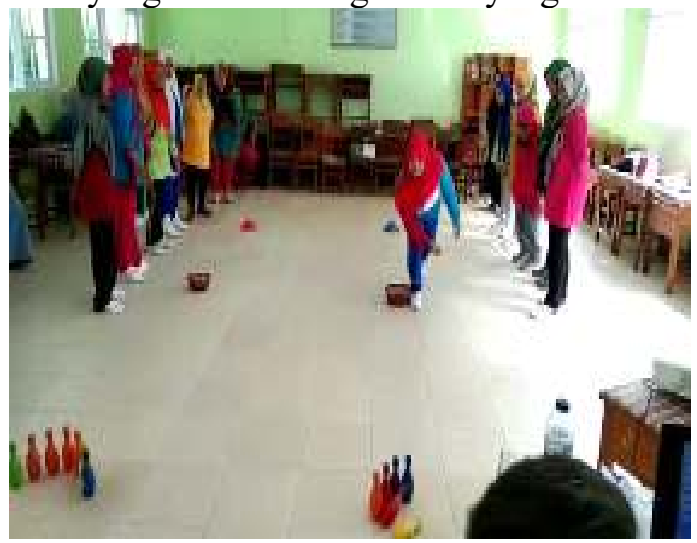

Gambar 7a. Praktek pembelajaran gerak dasar

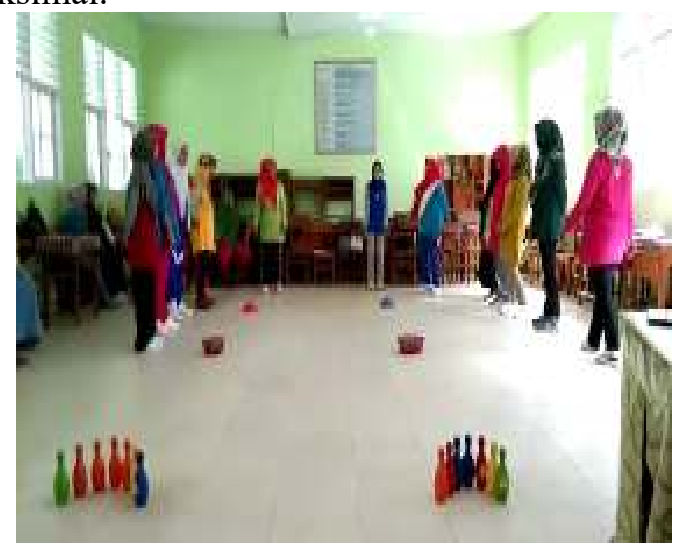

Gambar 7b. Praktek pembelajaran gerak dasar

4. Melakukan Pendampingan Dalam Implementasi Pembelajaran Gerak Dasar di PAUD/TK

Setelah kegiatan pengabdian dilakukan, langkah selanjutnya adalah pengabdi melakukan kegiatan monitoring kepada mitra, sebanyak 2 kali bertutur-turut. Kegiatan ini berfokus pada diskusi terhadap masalah-masalah yang ditemui oleh mitra selama mengaplikasikan ilmu yang telah didapatkan melalui pelatihan di sekolah masing-masing. Pendampingan dilakukan melalui ketua IGTKI masing-masing kecamatan di kabupaten Lima Puluh Kota, dimana para guru TK/PAUD di masing-masing kecamatan memasukkan program bahasan pelatihan dalam implementasi di tempat tugas mereka. Setiap IGTKI memberikan laporan kepada tim penngabdi tentang kemajuan, kendala atau tentang apa saja yang ditemui dilapangan. Tidak hanya itu komunikasi antara khalayak sasaran dengan pengabdi tetap dijalin secara baik melalui during dalam upaya menyebarluaskan ilmu yang telah didapatkan. 


\section{Dissemination and Training of Early Childhood Motion Skill Level Development for PAUD /}

Kindergarten and Elementary Teachers in Lima Puluh Kota District

${ }^{1}$ Lucy Pratama Putri, ${ }^{2}$ Ibnu Andli Marta, ${ }^{3}$ Oktarifaldi, ${ }^{4} \mathrm{Jonni}$, ${ }^{5}$ Yulifri, ${ }^{6} \mathrm{Kibadra},{ }^{7} \mathrm{Ali}$ Asmi, ${ }^{8} \mathrm{Hasriwandi}$ Nur, ${ }^{9} \mathrm{Nirwandi},{ }^{10} \mathrm{Erizal} \mathrm{N}$,

\section{HASIL DAN PEMBAHASAN}

Kegiatan pengabdian kepada masyarakat yang peneliti laksanakan, dilanjutkan dengan monitoring dan pendamingan terhadap mitra yang turut berpartisipasi dalam kegiatan ini. Pelaksanaan kegiatan monitoring dan pendamingan dilaksanakan 2 minggu pasca kegiatan penyampaian materi. Kegiatan pendampingan dan monitoring bertujuan agar tidak terjadi pergeseran persepsi pada mitra terhadap materi yang telah disampaikan dan agar mitra bisa berdiskusi dengan pengabdi terkait masalah-masalah yang terjadi di lapangan selama mitra mengimplementasikan ilmu yang didapatkan. Pengabdi juga melakukan evaluasi terhadap kegiatan ini dengan jalan memberikan kuesioner berupa beberapa pertanyaan yang terkait dengan pembelajaran gerak dasar sebelum dan sesudah kegaitan berlangsung.

Dalam pelaksanaan pengabdian di kabupaten Lima Puluh Kota ini, tidak terlihat kendala yang berarti. Khalayak mitra sangat mau dan antusias dalam menerima ilmu dari pengabdi. Selain itu, pemangku kebijakan di masing-masing kecamatan untuk anak usia dini sangat mendukung keberlangsungan kegiatan ini. Selain guru, pengawas dan kepala seksi PAUD dan TK kepala dinas pendidikan juga memfasilitasi pengabdi dan tim dengan menerbitkan surat keputusan kerjasama dengan pengabdi untuk jangka panjang dalam mengimplementasikan pembelajaran gerak dasar di kabupaten lima puluh kota. Berikut hasil yang pengabdi peroleh dari 24 orang responden:

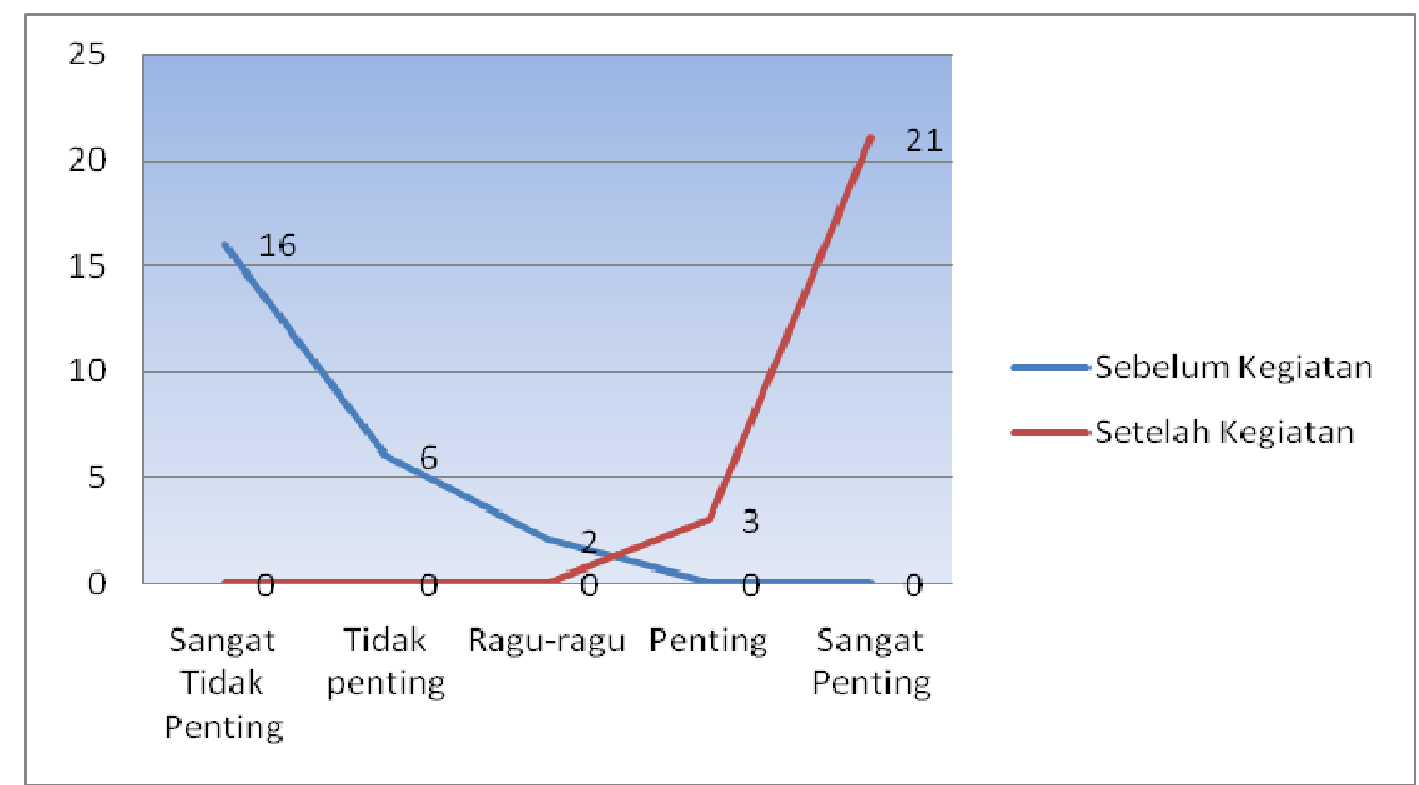

Gambar 8. Grafik peningkatan pengetahun guru PAUD/TK terhadap pembelajaran gerak dasar

Berdasarkan hasil evaluasi, sebelum kegiatan berlangsung ternyata sebanyak $67 \%$ guru PAUD/TK yang menganggap bahwa pembelajaran gerak dasar "Sangat Tidak Penting" untuk diajarkan pada anak usia dini. Sebanyak 25\% yang menganggap "Tidak Penting". Sisanya sebanyak $8 \%$ guru PAUD/TK yang masih "Ragu-ragu" apakah pembelajaran gerak dasar ini diperlukan oleh anak usia dini untuk menunjang perkembangan dan pertumbuhan, fisik, motorik, kognitif dan social anak. Setelah dilaksanakan penyampaian materi, pengabdi kembali membagikan angket untuk melihat respon dari mitra. Ternyata pengabdi mendapatkan respon positif terhadap kegiatan ini karena mitra menganggap bahwa memang kegiatan semacam inilah yang mereka butuhkan untuk turut serta serta mencerdasakan anak bangsa agar tujuan dari Pendidikan Nasional dapat tercapai sebagaimana mestinya.

Merujuk dari fenomena tersebut, tidak sedikit guru berasumsi yang kurang tepat, yaitu dengan menguasai keterampilan gerak tidak aka nada pengaruh yang signifikan terhadap kognitif bahkan akan mengganggu kognitif anak. Padahal secara teoritis melakukan aktivitas fisik seperti itu tidak hanya dapat meningkatkan kebugaran jasmani dan menghilangkan rasa jenih pada anak. Namun lebih jauh hal ini dapat mengembangkan kemampuan kognitif, afektif dan psikomotorik secara bersamaan. 


\section{Dissemination and Training of Early Childhood Motion Skill Level Development for PAUD / Kindergarten and Elementary Teachers in Lima Puluh Kota District}

${ }^{1}$ Lucy Pratama Putri, ${ }^{2}$ Ibnu Andli Marta, ${ }^{3}$ Oktarifaldi, ${ }^{4}$ Jonni, ${ }^{5}$ Yulifri, ${ }^{6}$ Kibadra, ${ }^{7}$ Ali Asmi, ${ }^{8}$ Hasriwandi Nur, ${ }^{9}$ Nirwandi, ${ }^{10}$ Erizal N,

Karena keterampilan gerak dasar yang dimiliki oleh anak akan berkorelasi dengan perkembangan kemampuan kognitif anak, seperti menulis, membaca dan berhitung (Diamond, 2000, Ericsson, 2008, Piek, Dawson, Smith, Gasson, 2008, Raczek, 2010, Westendorp, Hartman, Houwen, Smith, Visscher, 2011, Singh, Uijtdewilligen, Twisk, Mechelen, Chinapaw, van der Fels, Ewierike, Hartman, Elferink-, Smith, Visscher; mArcin, Sara, Andrzej, 2017).

Kegiatan ini menurut guru-guru sangat bermanfaan dan relevan dengan beberapa hasil penelitian, terbukti terdapat perbedaan kemampuan keterampilan gerak dasar khususnya object control antara kelompok anak yang diberi feedback langsung dan tidak langsung, ditemukan bahwa kemampuan gerak dasar anak yang diberikan feedback langsung memiliki nilai rata-rata yang lebih tinggi jika dibadingkan dengan keterampilan gerak dasar anak yang diberikan tidak langsung, Bakhtiar Dkk (2020). Maksud dari feedback yang pengabdi rujuk dari penelitian sebelumnya adalah, dengan telah direalisasikannya kegiatan pengabdian kepada masyarakat ini, diasumsikan bahwa guru akan memulai memberikan dan mentransfer ilmu yang pengabdi dan tim berikan ditempat tugas masingmasing. Dengan demikian tentunya akan meningkatkan keterampilan gerak dasat anak PAUD khususnya di kabupaten Lima Puluh Kota.

Menguasai gerak dasar pada saat usia dini khusunya di PAUD dan TK, akan membentu anak ketika sudah duduk di bangku sekolah dasar. Salahsatu yang perlu kita ketahui adalah jika anak memiliki keterampilan gerak maka akan mudah untuk menjalankan aktifitas fisik dehari-hari. Apabila kita perhatikan kondisi anak-anak sekolah dasar, pada umumnya senang berolahraga, dengan berolah raga maka akan menambah semangat anak untuk mengikuti pelajaran yang lainnya, Redawati, R., \& Asnaldi, A. (2017). Dengan demikian dapat dipahami bahwa setiap anak penting dan wajib menguasai keterampilan gerak dasar, tidak hanya untuk kesehatan, kemampuan motorik akan tetapi membantu anak dalam mengembangkan kognitif hingga menyelesaikan masalah.

\section{DISKUSI}

Pengabdi bersama Yayasan Sekora telah melakukan beberapa kegiatan pengabdian yang berfokus pada peningkatan kualitas pembelajaran gerak dasar pada anak usia dini di PAUD/TK yang ada Kota dan Kabupaten Sumatera Barat. Karena apabila kita melihat teori pertumbuhan dan perkembangan menyebutkan bahwa usia dini adalah golden age atau masa emas dari tahap perkembangan dan pertumbuhan anak, baik itu kognitif, afektif maupun psikomotorik sudah sepantasnya kita menitik beratkan perhatian pada golden age anak. Jika ingin menciptakan generasi emas, kita harus mampu meningkatkan kualitas kemampuan anak semenjak usia dini. Kedepanya kegiatan ini akan terus dilaksanakan agar tujuan dari Pendidikan Nasional dapat diwujudkan sebagaimana tertuang dalam UU No. 20 Tahun 2003 pasal 3 Tentang Sistem Pendidikan Nasional: "Tujuan pendidikan Nasional adalah untuk mengembangkan potensi peserta didik agar menjadi manusia yang beriman dan bertakwa kepada Tuhan Yang Maha Esa, berakhlak mulia, sehat, berilmu, cakap, kreatif, mandiri, dan menjadi warga negara yang demokratis serta bertanggung jawab".

\section{KESIMPULAN}

Kegiatan Pengabdian Kepada Masyarakat yang telah pengabdi lakukan di Kabupaten Lima Puluh Kota, menghasilakn kesimpulan sebagai berikut:

1. Kegiatan ini telah dilaksanakan tanpa adanya kendala yang berarti

2. Kegiatan Pengabdian Kepada Masyarakat ini memberikan gambaran pada orang tua, guru, Kepala Sekolah dan Dinas terkait tentang pentingnya mengajarkan keterampilan gerak pada anak serta memasukan unsur belajar gerak dalam materi pembelajaran yang diajarkan di PAUD/TK yang ada di Sumatera Barat, khususnya Kabupaten Lima Puluh Kota.

3. Kegiatan Pengabdian Kepada Masyarakat telah memberikan pengetahuan kepada guru PAUD/TK bagimana cara mernacang pembelajaran gerak dan menggunakan instrument TGMD2 untuk melakukan tes keterampilan gerak dasar yang terdiri dari kemampuan lokomotor dan objek control.

\section{PENGAKUAN}


Pengabdi mengucapkan terimakasih banyak pada Pemerintah Kabupaten Lima Puluh Kota melalui Dinas Pendidikan dan Kebudayaan yang telah memberikan pengabdi kesempatan untuk melakukan kegiatan pengabdian kepada massyarakat ini. Kemudian pengabdi juga mengucapkan terimkasih kepada TIM Pembelajaran Gerak Dasar Yayassan Sekolah Olahraga (SEKORA) serta rekan-rekan dosen yang turut membantu dalam suksenya acara ini. Selanjutnya ucapan terimakasih kepada mitra yang telah bersedia hadir.

\section{DAFTAR PUSTAKA}

Ali, A., Pigou, D., Clarke, L., \& McLachlan, C. (2017). Literature review on motor skill and physical activity in preschool children in new zealand.

Asnaldi, A., \& Kibadra, K. (2019). Sosialisasi Program Latihan Motor Ablity Kepada Asisten Pelatih Dojo Lembaga Karate-Do Indonesia Se-Kecamatan Koto Tangah. Jurnal Berkarya Pengabdian Masyarakat, 1(1), 67-74. https://doi.org/10.24036/JBA.V1I1.33

Bakhtiar, Syahrial. 2015. Merancang Pembelajaran Gerak Dasar Anak. Padang; UNP Press.

Bakhtiar, S., Oktarifaldi, O., \& Putri, L. P. (2019). Implementation of Learning and Fundamental Motor Skill Measurement of Early Childhood Motor Skill for PAUD Teachers in Padang Panjang City. Jurnal Humanities Pengabdian Kepada Masyarakat, 1(1), 36-47.

Bakhtiar, S., Khairuddin, K., \& Yelis, R. (2020). Pengaruh Umpan Balik, Koordinasi Terhadap Kemampuan Objek Kontrol Siswa Paud Kota Padang Panjang. Sporta Saintika, 5(1), 59-72.

Famelia, R., Goodway, J. D., Bakhtiar, S., \& Mardela, R. (2016, June). Investigating the motor competence and physical activity of Indonesian, Muslim preschoolers from urban and rural areas. In journal Of Sport \& Exercise Psychology (Vol. 38, pp. S33-S33). 1607 N MARKET ST, PO BOX 5076, CHAMPAIGN, IL 61820-2200 USA: HUMAN KINETICS PUBL INC.

Kokštejn, J., Musálek, M., Št’astný, P., \& Golas, A. (2017). Fundamental motor skills of Czech children at the end of the preschool period. Acta Gymnica, 47(4), 193-200.

Korbecki, M., Wawrzyniak, S., \& Rokita, A. (2017). Fundamental movement skills of six-to sevenyear-old children in the first grade of elementary school: A pilot study. Baltic Journal of Health and Physical Activity. The Journal of Gdansk University of Physical Education and Sport, 9(4).

Oktarifaldi, O., Syahputra, R., \& Putri, L. P. (2019). The Effect Of Agility, Coordination and Balance On The Locomotor Ability Of Students Aged 7 To 10 Years. Jurnal Menssana, 4(2), 190-200.

Pope, M. L., Liu, T., \& Getchell, N. (2011). Object-control skills in Hispanic preschool children enrolled in head start. Perceptual and Motor Skills, 112(1), 193-200.

Redawati, R., \& Asnaldi, A. (2017). Persepsi Guru-Guru Non Penjas terhadap Pembelajaran Pendidikan Jasmani Olahraga Kesehatan dan Rekreasi Gugus IV Sungai Jambu Kecamatan Pariangan. Sport Science, 17(1), 10-18.

Tsapakidou, A., Anastasiadis, T., Zikopoulou, D., \& Tsompanaki, E. (2014). Comparison of locomotor movement skills in 8-9 years old children coming from two areas of Thessaloniki with contrasting socioeconomic status. Asian Journal of Humanities and Social Studies (ISSN: 2321-2799), 2(01). 
Dissemination and Training of Early Childhood Motion Skill Level Development for PAUD / Kindergarten and Elementary Teachers in Lima Puluh Kota District

${ }^{1}$ Lucy Pratama Putri, ${ }^{2}$ Ibnu Andli Marta, ${ }^{3}$ Oktarifaldi, ${ }^{4}$ Jonni, ${ }^{5}$ Yulifri, ${ }^{6}$ Kibadra, ${ }^{7}$ Ali Asmi, ${ }^{8}$ Hasriwandi Nur, ${ }^{9}$ Nirwandi, ${ }^{10}$ Erizal N,

${ }^{11}$ Syahrial Bakhtiar

Ulrich, D. A. (2000) The Test of Gross Motor Development (Second ed). Austin: TX Pro-ed

Zipporah, M., Kadenyi, M., \& Maithya, P. (2016). Influence Of Teacher Related Factors On The Implementation Of Physical Education Syllabus In Public Primary Schools In Manga Sub County, Kenya. 